\title{
AUDIT-STAFF SCHEDULING: METHODS FOR THE MEDIUM-TERM LEVEL
}

\section{Andreas Schirmer, Christian-Albrechts-Universität Kiel Frank Salewski, Christian-Albrechts-Universität Kiel}

A survey conducted among 200 of the biggest German CPA firms shows that the process of audit-staff scheduling is usually divided into three distinct levels [1]. The first of these levels, the medium-term planning [2], assigns teams of auditors to audit engagements; then it constructs a schedule covering all the engagements' phases, e.g. preliminary, intermediate, and final audit, and determines the workload per auditor and week - on the basis of forty-hours-periods - over a planning horizon of between three and twelve months.

The problem is formulated in terms of a binary optimization model which is closely related to multi-mode resource-constraint project scheduling. Thereby, different teams are tally with different modes. Apart from job completion, time, resource, and precedence constraints this model comprises also so-called mode-identity constraints which guarantee that the assignment of a team to an engagement, once done, is never changed.

As a consequence, for solving the medium-term audit-staff scheduling problem, a general two-stage algorithmic scheme has been developed. In the first stage, the assignment of modes to engagements is done by choosing a mode for each engagement, according to regret values (generalized opportunity costs) which measure the worst-case consequence of not selecting a considered mode. In the second stage, following the general cperating scheme of parallel scheduling, the actual scheduling takes place, using heuristically obtained priority values.

Both stages use randomization to avoid some of the drawbacks of traditional, deterministic scheduling heuristics. Rather than selecting the candidate with the highest regret or priority value, they calculate selection probabilities proportional to these values and perform the selection process in a random way, according to the calculated probabilities. Due to this nondeterminism, repeated application will produce a set of solutions rather than one sole solution.

To evaluate the performance of the scheme, an experimental study was undertaken, in the course of which the scheme was applied to a sample of representative instances. The computational experience gained so far is promising. For most of the attempted instances feasible solutions were found. Further refinements on the priority rules are expected to lead to slightly better results.

\section{References}

[1] Salewski, F., A. Drexl (1993): Personaleinsatzplanung in Wirtschaftsprüfungsgesellschaften - Bestandsaufnahme und konzeptioneller Ansatz, to appear in: Zeitschrift für Betriebswirtschaft.

[2] Salewski, F., A. Schirmer, A. Drexl (1993): Auftragsorientierte Bildung von Prüferteams für die taktische Personaleinsatzplanung in Wirtschaftsprüfungsgesellschaften, Discussion Paper, Universität Kiel. 